\title{
Genetic epistasis of adiponectin and PPAR 2 genotypes in modulation of insulin sensitivity: a family-based association study
}

\author{
W.-S. Yang1, 2, C. A. Hsiung ${ }^{3}$, L.-T. Ho ${ }^{4}$, Y.-T. Chen ${ }^{5}$, C.-T. He 6 , J. D. Curb ${ }^{7}$, J. Grove ${ }^{7}$, T. Quertermous ${ }^{8}$, \\ Y.-D. I. Chen ${ }^{9}$, S.-S. Kuo', L.-M. Chuang', 2 the Sapphire Study Group \\ ${ }^{1}$ Department of Internal Medicine, National Taiwan University Hospital, Taipei, Taiwan \\ 2 Graduate Institute of Clinical Medicine, National Taiwan University, Taipei, Taiwan \\ ${ }^{3}$ Division of Biostatistics and Bioinformatics, National Health Research Institutes, Taipei, Taiwan \\ ${ }^{4}$ Department of Medical Research and Education, Taipei Veterans General Hospital; and Faculty of Medicine, School of Medicine, \\ National Yang-Ming University, Taipei, Taiwan \\ ${ }^{5}$ Department of Endocrinology and Metabolism, Taichung Veterans General Hospital, Taichung, Taiwan \\ ${ }^{6}$ Department of Endocrinology and Metabolism, Tri-Service General Hospital, Taipei, Taiwan \\ ${ }^{7}$ University of Hawaii, Honolulu, Hawaii, USA \\ ${ }^{8}$ Stanford University School of Medicine, Stanford, California, USA \\ ${ }^{9}$ Cedars-Sinai Medical Center, Los Angeles, California, USA
}

\begin{abstract}
Aims/hypothesis. Genetic interactions in modulating the phenotypes of a complex trait, such as insulin sensitivity, were usually taken for granted. However, this has not been commonly shown. Previous studies have suggested that both PPAR 2 and adiponectin genes could influence insulin sensitivity. Therefore it is likely that they could modulate insulin sensitivity through gene to gene interactions.

Methods. We genotyped 1793 subjects of Chinese and Japanese descendents from 601 hypertensive families recruited in Sapphire study for a $T 94 G$ in the adiponectin gene exon 2 and the PPAR 2 Prol2Ala polymorphisms. Serum insulin concentrations and insulin resistance index $\left(\mathrm{HOMA}_{\mathrm{IR}}\right)$ were used as the markers of insulin sensitivity.

Results. We found that the $T$ allele of adiponectin gene was associated with a higher Ins60 and higher area under curve of insulin (AUCi) in OGTT utilizing
\end{abstract}

all subjects in a mixed model that corrected for family effects. Important interactions between adiponectin and $P P A R \gamma 2$ genotypes were found in fasting insulin concentrations (Ins0), insulin concentrations at 2-h (Ins120) in OGTT and insulin resistance index $\left(\mathrm{HOMA}_{\mathrm{IR}}\right)$. The main effects of the PPAR 2 genotypes were in the plasma glucose concentrations in OGTT. In contrast, the main effects of adiponectin genotypes were in every insulin variable, including Ins0,

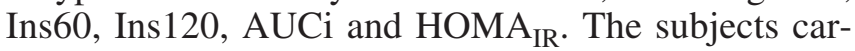
rying the adiponectin $G$ allele and the PPAR 2 Ala 12 allele seemed to be more insulin sensitive.

Conclusion/interpretation. These results showed that adiponectin is a genetic factor associated with insulin sensitivity. Interactions with PPAR 22 genotypes modified this association. [Diabetologia (2003) 46:977-983]

Keywords Adiponectin, PPAR 2 , polymorphisms, gene interaction, insulin sensitivity.

to be the fundamental pathophysiology of T2DM [2]. As a classical example of polygenic (also called multifactorial or complex) diseases, the pathogenesis of T2DM is attributed to the collective actions of many genetic and environmental factors and the complex interactions among them [3]. The contribution of gene to gene interactions in shaping the phenotypes of T2DM, such as insulin sensitivity, is usually taken for granted. However, it is only occasionally shown $[4,5]$.

Among many potential thrifty genes, the Pro12Ala variants of the human PPAR 2 gene have been extensively surveyed in many genetic association studies by other investigators $[6,7,8]$. Previously we reported the association of the PPAR 2 Ala12 variant with bet-
Corresponding author: Dr. L.-M. Chuang, Department of Internal Medicine, National Taiwan University Hospital, 7 Chung-Shan South Road, Taipei, Taiwan

E-mail: leeming@ha.mc.ntu.edu.tw

Abbreviations: PPAR, peroxisome proliferator-activated receptor; HOMA, homeotasis model assessment; T2DM, Type 2 diabetes mellitus. 
ter glucose tolerance and insulin sensitivity among subjects from Japanese and Chinese hypertension families in the Stanford Asia Pacific Program in Hypertension and Insulin Resistance (Sapphire) study [9]. Due to its family-based study design utilizing the comparisons between siblings, the genetic association study in Sapphire was expected to have better control in early childhood environmental factors and genetic background than a population-based genetic association study $[9,10,11]$.

The other sensible genetic candidates for T2DM are adipose-derived secreted molecules regulated by $P P A R \gamma 2$, such as leptin, resistin and adiponectin. Among them, the recombinant adiponectin protein has been shown in mice to be capable of lowering plasma glucose and fatty acids, improving insulin sensitivity and reducing body weight $[12,13,14]$. It has also been reported that adiponectin genotypes in humans influence insulin sensitivity and the risk for T2DM $[15,16,17,18,19]$. Recent studies using knockout mice confirmed these biological functions of adiponectin $[20,21]$.

We have shown that treating T2DM patients with rosiglitazone, a PPAR $\gamma 2$ agonist raised their plasma adiponectin concentrations by more than two-fold [22]. The other investigators have also shown that the administration of glitazones increased the expression of adiponectin in humans as well as in animals and in cultured adipocytes $[23,24,25,26]$. These results together suggest a possibility of genetic interactions between PPAR $\gamma 2$ and adiponectin, and its attribution to insulin sensitivity.

In this study, we investigated the association of adiponectin $T 94 G$ polymorphism with metabolic phenotypes and the effects of its interaction with the PPAR 2 Pro12Ala polymorphism on these phenotypes among the large cohort from the Sapphire $[9,10]$. We found that the $T$ allele of adiponectin was associated with post-glucose load hyperinsulinaemia. The main effects of the adiponectin and PPAR 2 genotypes and the genetic interactions between them on the metabolic variables were revealed in further analyses. The subjects having both the $G$ allele of adiponectin and the Ala12 allele of PPAR 2 seemed to be more insulin sensitive.

\section{Subjects and methods}

Subjects and phenotypic characterization. The characteristics of study population, the inclusion and exclusion criteria of Sapphire study were detailed in several previous publications $[9,10]$. Notably, diabetic subjects diagnosed based on the WHO criteria were excluded [27]. This study incorporated both the concordant (both hypertension) and the discordant sibling-pairs (one hypertension, the other hypotension) in design. A total of 2525 subjects of Japanese or Chinese descendents were recruited from 6 centres at San Francisco, Hawaii and Taiwan. In this report, 1793 subjects including parents and siblings from 601 families were genotyped. Written informed consent was obtained from all participants. The study was approved by the ethics board of each participating institute. Characterization of the subjects by fasting plasma glucose, insulin, triglyceride, total cholesterol, lipoprotein profile, and anthropometric measurements, including height, weight, waist and hip circumference were described in detail previously [9, 10]. A 75-g OGTT was carried out and plasma glucose and insulin concentration at $1-\mathrm{h}$ and 2 -h post-glucose load were measured $[9,10]$. The fasting plasma sample was obtained right before the OGTT was conducted.

Extraction of genomic DNA and genotyping. Total genomic DNA was purified from peripheral blood leukocytes using a DNA extraction kit of Puregene (Minneapolis, Minn., USA), following the manufacturer's protocol. The primers used for PCR amplification for the exon 2 of human adiponectin gene were: 5'-TAG AAG TAG ACT CTG CTG AGA TG-3' and 5'-CTC CCT GTG TCT AGG CCT TAG-3'. The PCR reactions were carried out in a total volume of $15 \mu$ containing $20 \mathrm{ng}$ of genomic DNA with an initial denaturation at $94^{\circ} \mathrm{C}$ for $5 \mathrm{~min}$, followed by denaturing at $94^{\circ} \mathrm{C}$ for $30 \mathrm{~s}$, annealing at 68 to $60^{\circ} \mathrm{C}$ for $1 \mathrm{~min}$ with the annealing temperature stepping down $2^{\circ} \mathrm{C}$ for every five cycles, and polymerization at $72^{\circ} \mathrm{C}$ for $40 \mathrm{~s}$; then by a final extension at $72^{\circ} \mathrm{C}$ for $10 \mathrm{~min}$. Of the amplified DNA $4 \mu \mathrm{l}$ was digested with the BspHI enzyme (New England BioLabs, Beverly, Mass., USA), and then electrophoresed on a $2 \%$ agarose gel. The resulting fragment of PCR was 422 base pairs (bp). As the $T 94 G$ substitution abolished a $B s p H I$ restriction site, two fragments of 265 and $157 \mathrm{bp}$ after digestion indicated the presence of $T$ allele. This polymorphism is equivalent to the SNP45 described elsewhere [16]. The genotyping of PPAR 2 Prol2Ala was published previously [9].

Statistical analyses. Association analysis for adiponectin genotypes - All variables were in SI units except that in $\mathrm{HOMA}_{\mathrm{IR}}$. The data were given in means and S.E. In order to compare each outcome variable between the $G$ variant-carrying individuals (including the genotypes $T / G$ and $G / G$ ) and their siblings with the genotype $T / T$, only the siblings with discordant genotypes in $T 94 G$ polymorphism of the adiponectin gene were included in the analysis. Paired analysis was used to test whether there was difference in variables of interest between the siblings discordant for genotypes after adjustment for age, sex, BMI, ethnicity and area of enrollment by using analysis of covariance with these variables as covariates. The analyses were done using the SAS version 8.0 PROC GLM. We also carried out analysis of covariance using a mixed model to assess whether the adiponectin genotypes affect the outcome variables controlling for covariates age, sex, BMI, ethnicity and area of enrollment as fixed effects, and controlling for clustering among families as a random effect. The analyses were performed using the SAS 8.0 PROC MIXED. All statistical tests were two-tailed. A $p$ value of less than 0.05 was considered statistically significant.

Analyses on adiponectin gene and PPAR 2 gene interactions. In order to assess the interactions between the adiponectin and $P P A R \gamma 2$ genotypes, we carried out an analysis of covariance using a mixed model to evaluate the contribution of the main effects of adiponectin T49G and PPAR 2 Prol2Ala respectively, and their interactions for each variable of interest in the same model controlling for covariates age, sex, BMI ethnicity and area of enrollment as fixed effects and entering family as a random effect. The analyses were done using the SAS 8.0 PROC MIXED. 
Table 1. The proportions (\%) and the numbers of subjects with specific adiponectin T94G genotypes and alleles among Chinese or Japanese subjects and hypertensive probands

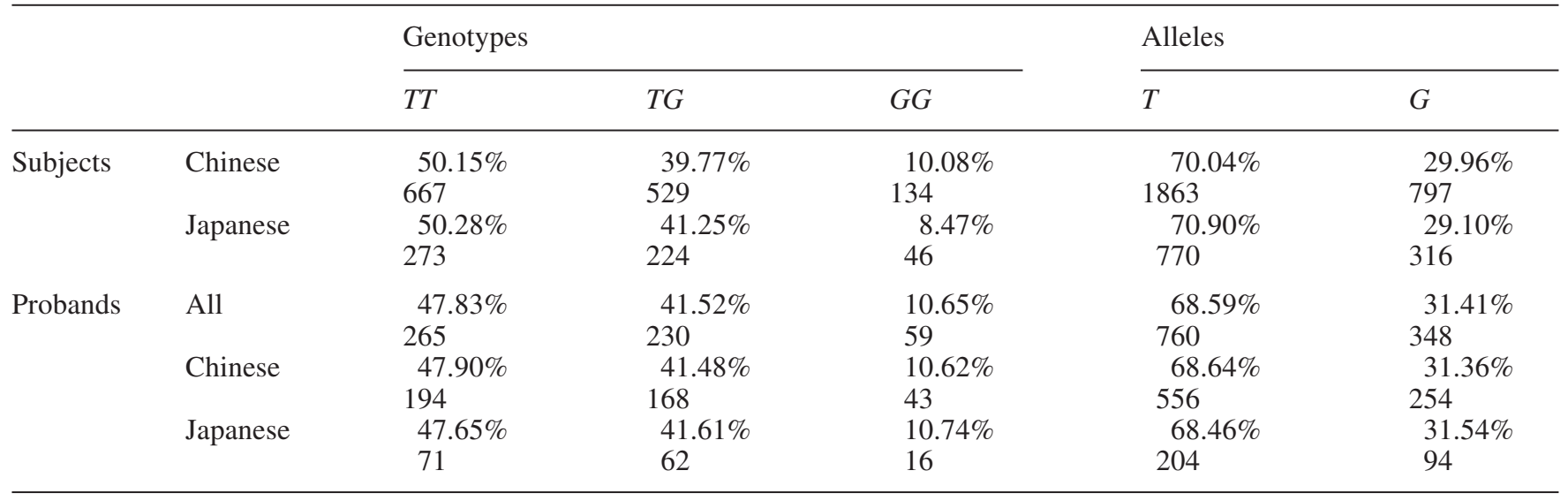

Table 2. Characteristics of the subjects discordant for the adiponectin genotypes are compared in subjects with the $T / T$ vs. those with the $T / G$ or $G / G$

\begin{tabular}{|c|c|c|c|}
\hline Variables & $\begin{array}{l}T / T(n=844) \\
\text { Means } \pm \text { S.E. }\end{array}$ & $\begin{array}{l}T / G \text { or } G / G(n=869) \\
\text { Means } \pm \text { S.E. }\end{array}$ & $p=* *$ \\
\hline Gender (male/female) & $372 / 472$ & $389 / 480$ & NS \\
\hline Area (Taiwan/San Francisco/Hawaii) & $513 / 96 / 235$ & $509 / 92 / 268$ & $\mathrm{NS}$ \\
\hline Age (years) & $50.78 \pm 0.38$ & $50.88 \pm 0.38$ & NS \\
\hline BMI $\left(\mathrm{kg} / \mathrm{m}^{2}\right)$ & $25.65 \pm 0.16$ & $25.96 \pm 0.16$ & NS \\
\hline
\end{tabular}

** NS for $p>0.1$

The differences of several variables between the subjects with different adiponectin genotypes within fixed PPAR 22 genotypes after adjusting for age, sex, ethnicity, BMI, area of enrollment and family effects were compared. The values/bars reported are the least square means for each subgroup. The $p$ values were obtained using the SAS 8.0 PROC MIXED. The SAS statistical program is from the SAS Institute (Cary, N.C., USA).

\section{Results}

The genotype and allele frequencies of adiponectin $T 94 G$ polymorphism in Japanese and Chinese subjects were comparable (Table 1). The genotype and allele frequencies in the hypertensive probands were similar and did not deviate from Hardy-Weinberg equilibrium (Table 1). The genotype and allele frequencies, and the basic characteristics of these subjects categorized by the PPAR 2 genotypes were reported previously [9]. Using a sibling-based comparison for phenotypic variables, we found that the subjects with the $T / T$ genotype ( $n=282)$ had higher mean plasma insulin concentration at $1 \mathrm{~h}$ (Ins60) during OGTT than that of the sibs with the discordant genotypes ( $T / G$ and $G / G$, $n=312$ ) after adjustment for age, sex, BMI, ethnicity and the area of enrollment $(562 \pm 27$ vs. $483 \pm 18$ pmol/l, $p=0.0067)$. The difference in the AUCi in OGTT was of borderline statistical significance $(828 \pm 37$ vs. $743 \pm 27$ pmol.h/l, $p=0.0578)$. The differences between discordant adiponectin genotypes in the other variables did not reach statistical significance (data not shown).

To confirm the above findings, we also used a mixed model to correct for familial effects. This method enabled us to include more subjects for analyses. The basic characteristics of the subjects included in this analysis were shown in Table 2. After adjusting for age, sex, BMI, ethnicity and area of enrollment, only the means in Ins60 and AUCi in OGTT were different between subjects with the $T / T$ genotype and those otherwise (Table 3 ). Post-glucose load hyperinsulinaemia among subjects with the $T / T$ genotype in order to normalize plasma glucose concentrations shown in these two analyses suggests that they could be more insulin resistant. We also carried out the analyses by categorizing the subjects into three adiponectin genotypes ( $n=844$ of $T / T, n=701$ of $T / G$ and $n=168$ of $G / G)$. The results were quite similar, only the mean Ins60 ( $525 \pm 18$ vs. $455 \pm 20$ vs. $461 \pm 35 \mathrm{pmol} / \mathrm{l}$, $p=0.0035)$ and AUCi $(785 \pm 26$ vs. $702 \pm 28$ vs. $719 \pm 50$ pmol.h/l, $p=0.0204)$ were significantly different among the three genotypes. The differences were 
Table 3. Comparisons of metabolic variables between subjects with discordant adiponectin genotypes after adjustment for age, sex, BMI, ethnicity and area of enrollment using a mixed model corrected for family effects

\begin{tabular}{lccc}
\hline Variables* & $\begin{array}{l}T / T(n=844) \\
\text { Means } \pm \text { S.E. }\end{array}$ & $\begin{array}{l}T / G \text { or } G / G(n=869) \\
\text { Means } \pm \text { S.E. }\end{array}$ & $p=* * *$ \\
\hline Glu0 & $5.35 \pm 0.05$ & $5.31 \pm 0.05$ & NS \\
Glu60 & $9.52 \pm 0.14$ & $9.35 \pm 0.14$ & $\mathrm{NS}$ \\
Glu120 & $7.81 \pm 0.14$ & $7.71 \pm 0.14$ & $\mathrm{NS}$ \\
AUCg & $16.11 \pm 0.21$ & $15.86 \pm 0.21$ & $\mathrm{NS}$ \\
Ins0 & $54.5 \pm 1.5$ & $53.4 \pm 1.5$ & $\mathrm{NS}$ \\
Ins60 & $525.0 \pm 18.4$ & $455.9 \pm 18.4$ & $\mathbf{0 . 0 0 0 8}$ \\
Ins120 & $475.3 \pm 20.0$ & $447.1 \pm 20.0$ & $\mathrm{NS}$ \\
AUCi & $784.7 \pm 26.3$ & $705.2 \pm 26.3$ & $\mathbf{0 . 0 0 5 6}$ \\
HOMA & $1.84 \pm 0.06$ & $1.84 \pm 0.06$ & $\mathrm{NS}$
\end{tabular}

*Abbreviations: Glu, plasma glucose at the specific time point in OGTT; Ins, plasma insulin at the specific time point in OGTT; AUCg, area under curve of plasma glucose in OGTT, AUCi, area under curve of plasma insulin in OGTT
** HOMA: homeostasis model assessment calculated by [Insu$\left.\operatorname{lin} / 22.5 \mathrm{e}^{-\operatorname{In}(\text { Glucose })}\right]$

*** pvalues greater than or equal to 0.1 are marked NS (not significant), $p$ values less than 0.05 are in bold

Table 4. Significance levels of the adiponectin or PPAR 2 genotypes on the main effects and their interactions after adjustment for age, sex, ethnicity, BMI, and area of enrollment using a mixed model corrected for family effects

\begin{tabular}{|c|c|c|c|c|c|c|}
\hline \multirow[t]{2}{*}{ Variables* } & \multicolumn{2}{|c|}{$\begin{array}{l}\text { Adiponectin } \mathrm{T} 94 \mathrm{G} \\
\text { Main effects }\end{array}$} & \multicolumn{2}{|c|}{$\begin{array}{l}\text { PPAR } \gamma 2 \text { Pro12Ala } \\
\text { Main effects }\end{array}$} & \multicolumn{2}{|l|}{ Interactions } \\
\hline & $\mathrm{F}($ d.f.s $)=* *$ & $p=$ & $\mathrm{F}($ d.f.s $)=$ & $p=$ & $F($ d.f.s $)=$ & $p=$ \\
\hline Glu0 & $3.61(1,811)$ & 0.0671 & $0.36(1,811)$ & 0.5491 & $2.96(1,811)$ & 0.0859 \\
\hline Glu60 & $0.47(1,687)$ & 0.4951 & $5.76(1,687)$ & 0.0167 & $0.01(1,687)$ & 0.9271 \\
\hline Glu120 & $0.37(1,715)$ & 0.5459 & $2.47(1,715)$ & 0.1167 & $0.09(1,715)$ & 0.7640 \\
\hline Ins60 & $8.64(1,696)$ & 0.0034 & $0.58(1,691)$ & 0.4468 & $1.81(1,696)$ & 0.1795 \\
\hline Ins 120 & $5.54(1,722)$ & 0.0189 & $0.68(1,722)$ & 0.4083 & $4.09(1,722)$ & 0.0435 \\
\hline AUCi & $9.07(1,682)$ & 0.0027 & $0.73(1,682)$ & 0.3937 & $3.32(1,682)$ & 0.0691 \\
\hline $\mathrm{HOMA}_{\mathrm{IR}}$ & $4.20(1,807)$ & 0.0408 & $0.64(1,807)$ & 0.4255 & $5.90(1,807)$ & 0.0154 \\
\hline
\end{tabular}

** F(d.f.s): F-value (degrees of freedom for the numerator and denominator of the relevant $\mathrm{F}$ statistics)

primarily between the $T / T$ and the other two genotypes, suggesting a dominant effect of the $G$ allele in association with insulin sensitivity. Thus this allowed us to pool $G / T$ and $G / G$ genotypes together in all the analyses. No significant difference among the three genotypes was observed in the other variables (data not shown).

Next we investigated the effects of genetic interactions between the adiponectin T94G and the PPAR 2 Pro12Ala polymorphisms. Previously, we found in the same study population that the PPAR 2 Ala12 variant was associated with better glucose tolerance at 0 (Glu0) and $1 \mathrm{~h}$ (Glu60) in OGTT and with lower insulin resistant index by HOMA (HOMA ${ }_{\text {IR }}$ ) [9]. Using two-way ANOVA analysis, we found that there were significant interactions between the adiponectin and $P P A R \gamma 2$ genotypes in insulin concentrations at 0 (Ins0) and $2 \mathrm{~h}$ (Ins120) in OGTT and HOMA $\mathrm{IR}_{\mathrm{R}}$, with adjustment for age, sex, BMI, ethnicity and area of enrollment, whereas their interactions in Glu0 and
AUCi were of borderline significance (Table 4). Interestingly, the main effects of adiponectin genotypes were all significant on every parameter (Ins0, Ins60, Ins120 and AUCi) of insulin in OGTT and HOMA $\mathrm{IR}$. The main effect of the adiponectin genotypes on Glu0 was of borderline significance (Table 4). In contrast, the main effects of PPAR 2 genotypes were only significant on Glu60 and area under curve of glucose (AUCg) in OGTT (Table 4).

To clearly illustrate the effects of interactions, these subjects were grouped by their genotypes. It was apparent that the subjects carrying both the adiponectin $G$ and PPAR 2 Ala 12 alleles were more insulin sensitive. They tended to have lower fasting plasma glucose and insulin, plasma insulin concentrations in

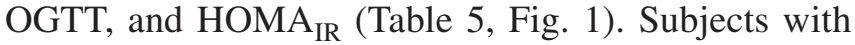
the adiponectin $G$ allele even when coupled with PPAR 2 Pro/Pro still had lower insulin concentrations at $1 \mathrm{~h}$ and AUCi in OGTT than subjects with the $T / T$ genotype (Table 5 and Fig. 1A). 

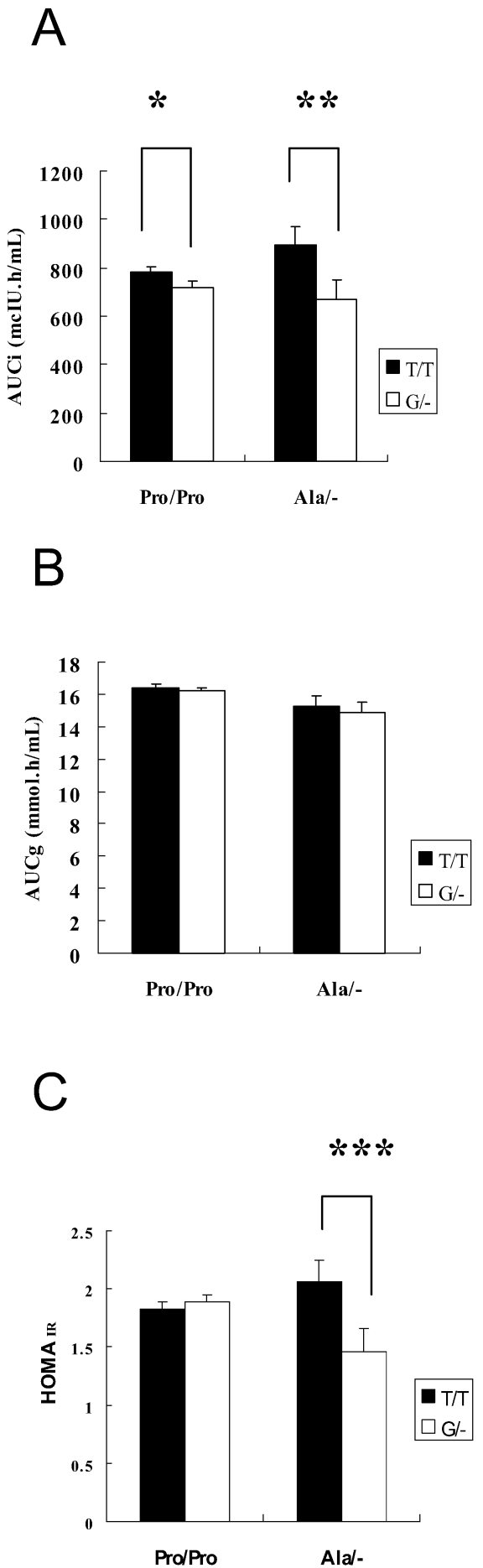

Fig. 1. A Comparisons of AUCi between the subjects with different combinations of the adiponectin and PPAR 2 genotypes, the bars show means \pm S.E., $* p=0.0357, * * p=0.0118$. B Comparisons of AUCg between the subjects with different combinations of the adiponectin and PPAR 2 genotypes, the bars showed means \pm S.E. C Comparisons of HOMA $\mathrm{HR}_{\mathrm{IR}}$ between the subjects with different combinations of the adiponectin and PPAR 2 genotypes, the bars showed means \pm S.E., $* * * p=0.0201$
Table 5. Comparisons between the subjects with different combinations of adiponectinand PPAR 2 genotypes. The $p$ values in the $1^{\text {st }}$ column from the right indicate the comparisons between the different adiponectingenotypes within a group with the same PPAR 2 genotypes. The $p$ values at the bottom indicate the comparisons between the different $P P A R \gamma 2$ genotypes within a group with the same adiponectingenotypes

\begin{tabular}{|c|c|c|c|c|}
\hline \multirow[t]{2}{*}{ Variables } & \multirow{2}{*}{$\begin{array}{l}P P A R \gamma 2 \\
\text { genotypes }\end{array}$} & \multicolumn{2}{|c|}{ Adiponectin genotypes } & \multirow[t]{2}{*}{$p=$} \\
\hline & & $\mathrm{T} / \mathrm{T}$ & G/- & \\
\hline \multirow[t]{2}{*}{$n$} & Pro/Pro & 779 & 804 & \\
\hline & Ala/- & 63 & 62 & \\
\hline \multirow[t]{2}{*}{ Glu0 } & Pro/Pro & $5.34 \pm 0.05$ & $5.33 \pm 0.05$ & $\mathrm{NS}$ \\
\hline & Alal- & $5.46 \pm 0.15$ & $5.08 \pm 0.16$ & 0.0649 \\
\hline$p=$ & & NS & NS & \\
\hline \multirow[t]{2}{*}{ Glu60 } & Pro/Pro & $9.57 \pm 0.14$ & $9.41 \pm 0.14$ & NS \\
\hline & Ala/- & $8.90 \pm 0.38$ & $8.69 \pm 0.40$ & NS \\
\hline$p=$ & & 0.0833 & 0.0721 & \\
\hline \multirow[t]{2}{*}{ Glu120 } & Pro/Pro & $7.85 \pm 0.14$ & $7.76 \pm 0.14$ & NS \\
\hline & Ala/- & $7.46 \pm 0.39$ & $7.21 \pm 0.42$ & NS \\
\hline$p=$ & & NS & NS & \\
\hline \multirow[t]{2}{*}{ AUCg } & Pro/Pro & $16.18 \pm 0.22$ & $15.95 \pm 0.21$ & NS \\
\hline & Ala/- & $15.27 \pm 0.58$ & $14.82 \pm 0.61$ & NS \\
\hline$p=$ & & NS & 0.0618 & \\
\hline \multirow[t]{2}{*}{ Ins0 } & Pro/Pro & $54.2 \pm 1.6$ & $54.2 \pm 1.5$ & NS \\
\hline & Alal- & $59.1 \pm 4.4$ & $45.1 \pm 4.7$ & 0.0234 \\
\hline$p=$ & & NS & 0.0554 & \\
\hline \multirow[t]{2}{*}{ Ins60 } & Pro/Pro & $519.3 \pm 19.0$ & $459.1 \pm 18.9$ & 0.0050 \\
\hline & Ala/- & $599.8 \pm 52.9$ & $439.5 \pm 55.3$ & 0.0256 \\
\hline$p=$ & & NS & NS & \\
\hline \multirow[t]{2}{*}{ Ins120 } & Pro/Pro & $467.0 \pm 20.5$ & $453.2 \pm 20.5$ & $\mathrm{NS}$ \\
\hline & Ala/- & $479.5 \pm 54.8$ & $410.8 \pm 58.6$ & 0.0225 \\
\hline$p=$ & & 0.0430 & NS & \\
\hline \multirow[t]{2}{*}{$\mathrm{AUCi}$} & Pro/Pro & $774.5 \pm 27.1$ & $711.8 \pm 26.8$ & 0.0357 \\
\hline & Ala/- & $916.4 \pm 74.3$ & $665.8 \pm 76.8$ & 0.0118 \\
\hline$p=$ & & 0.0605 & NS & \\
\hline \multirow{2}{*}{$\mathrm{HOMA}_{\mathrm{IR}}$} & Pro/Pro & $1.83 \pm 0.07$ & $1.88 \pm 0.07$ & NS \\
\hline & Ala/- & $2.04 \pm 0.19$ & $1.44 \pm 0.20$ & 0.0201 \\
\hline$p=$ & & NS & 0.0294 & \\
\hline
\end{tabular}

\section{Discussion}

In this report, we showed that the adiponectin $T 94 G$ genotypes indeed were associated with the variation in insulin sensitivity, indicated indirectly by the serum insulin concentrations and insulin resistance index by HOMA $\left(\mathrm{HOMA}_{\mathrm{IR}}\right)$, in a cohort of Chinese and Japanese hypertension families recruited in the Sapphire study. The subjects with the $T / T$ genotype had higher post-glucose load insulin concentrations but similar glucose concentrations than those with the other genotypes, indicating insulin resistance associated with $T / T$ genotypes. It should be noted that diabetic subjects were excluded in the recruitment of Sapphire study [10]. Compared with four recent population-based genetic association studies $[15,16,17,18]$, the advantage of the current study is that this is a family-based association study utilizing siblings as control subjects. As they share similar genetic and environmental backgrounds with the population control subjects, the ob- 
served phenotypic differences between them are more likely the results of genetic differences in interest [11].

There has been a great interest in tackling the genetic make-up of human complex traits or diseases, such as diabetes, obesity and hypertension. Although a huge amount of genetic data has been accumulated in the past, not very many have addressed the issue of genetic interactions [4, 5]. To our knowledge, our study is one of the earliest to investigate the genetic interactions in connection with insulin resistance. Significant interactions between the genotypes of adiponectin and PPAR 2 in relation to fasting insulin and post-glucose load insulin concentration at $2 \mathrm{~h}$ and $\mathrm{HOMA}_{\mathrm{IR}}$ were noted, providing some genetic evidence in humans that these two genes could participate either in the same pathway or in two interdependent pathways related to the biological processes of insulin sensitivity. Consistent with this, previous studies in cell culture, in animals and in humans have shown that adiponectin expression either at mRNA or at protein levels could be up-regulated by PPAR $\gamma 2$ activation $[21,22,23,24,25]$. This study has shown that a genetic association study is capable of detecting genetic epistasis.

The molecular mechanisms behind the genetic interactions between adiponectin and PPAR 2 genotypes are not clear. The $T 94 G$ polymorphism of adiponectin is a silent mutation for Gly15 (GGT to GGG). We speculated that it might be in linkage dis-equilibrium with the other genetic alterations, probably a regulatory mutation. In contrast, the PPAR 2 Ala 12 variant was previously shown to have reduced transactivating ability [8]. Although only a half-site of PPAR $\gamma$ response element (PPRE) was recognized in the proximal promoter of adiponectin by sequence analysis, synthetic PPAR $\gamma 2$ agonists were shown to enhance transcription of luciferase driven by the proximal $2 \mathrm{~kb}$ of adiponectin promoter [23]. How PPAR $\gamma 2$ variants might activate the adiponectin gene in different promoter contexts is an important question to address in the future.

In conclusion, we found that the $T 94 G$ polymorphism of the adiponectin gene was associated with insulin sensitivity, represented by serum insulin levels and $\mathrm{HOMA}_{\mathrm{IR}}$, in the subjects from a large hypertensive family cohort. More importantly, the effect of adiponectin was modified by the PPAR 2 Prol2Ala genotypes, indicating a genetic interaction in association with insulin sensitivity. These observations suggest that both the adiponectin and PPAR 2 genes and the interactions between them could play a role in the etiopathogenesis of insulin resistance.

Acknowledgements. The authors would like to thank Ms. C.-L. Chao and K.-C. Lee for their technical assistance. We thank patients and their families for participating in this study. We also thank S. Mockrin and S. Old of the National Heart, Lung and Blood Institute, and the other members of the Sapphire project for their help. This study was supported by grants
(NSC 85-2331-B002-350Y, NSC 86-2314-B002-345Y, NSC 87-2312-B002-021Y, and NSC 91-3112-B-002-019) from the National Science Council, a grant (BS-090-pp-01) from National Health Research Institutes, a grant from the Department of Education (89-B-FA01-1-4), Taiwan, R.O.C. and a grant (UO1 HL54527-0151) from the National Heart Lung and Blood Institute (USA). We also apologize to the authors whose work on PPAR 2 could not be cited here because of the limitations on the number of references.

\section{References}

1. Zimmet P, Alberti KGMM, Shaw J (2001) Global and societal implications of diabetes epidemic. Nature 414:782787

2. Reaven GM (1988) Role of insulin resistance in human disease. Diabetes 37:1595-1607

3. Froguel P, Velho G (2001) Genetic determinants of type 2 diabetes. Recent Prog Horm Res 56:91-105

4. Jansen H, Waterworth DM, Nicaud V, Ehnholm C, Talmud PJ (2001) Interaction of the common apolipoprotein C-III (APOC3-482C $>$ T) and hepatic lipase (LIPC-514C $>$ T) promoter variants affects glucose tolerance in young adults. European Atherosclerosis Research Study II (EARS-II). Ann Hum Genet 65:237-243

5. Hsueh WC, Cole SA, Shuldiner AR et al. (2001) Interactions between variants in the beta3-adrenergic receptor and peroxisome proliferator-activated receptor-gamma2 genes and obesity. Diabetes Care 24:672-677

6. Altshuler D, Hirschhorn JN, Klannemark M et al. (2000) The common PPARgamma Pro12Ala polymorphism is associated with decreased risk of type 2 diabetes. Nat Genet 26:76-80

7. Beamer BA, Yen CJ, Andersen RE et al. (1998) Association of the Pro12Ala variant in the peroxisome proliferatoractivated receptor-gamma2 gene with obesity in two Caucasian populations. Diabetes 47:1806-1808

8. Deeb SS, Fajas L, Nemoto M et al. (1998) Pro12Ala substitution in PPARgamma2 associated with decreased receptor activity, lower body mass index and improved insulin sensitivity. Nat Genet 20:284-287

9. Chuang LM, Hsiung CA, Chen YD et al. (2001) Siblingbased association study of the PPARgamma2 Pro12Ala polymorphism and metabolic variables in Chinese and Japanese hypertension families: a SAPPHIRe study. Stanford Asian-Pacific Program in Hypertension and Insulin Resistance. J Mol Med 79:656-664

10. Ranade K, Wu KD, Risch N et al. (2001) Genetic variation in aldosterone synthase predicts plasma glucose levels. Proc Natl Acad Sci USA 98:13219-13224

11. Stumvoll M, Haring H (2002) The peroxisome proliferatoractivated receptor-gamma2 Pro12Ala polymorphism. Diabetes 51:2341-2347

12. Fruebis J, Tsao TS, Javorschi S et al. (2001) Proteolytic cleavage product of $30-\mathrm{kDa}$ adipocyte complement-related protein increases fatty acid oxidation in muscle and causes weight loss in mice. Proc Natl Acad Sci USA 98:20052010

13. Berg AH, Combs TP, Du X, Brownlee M, Scherer PE (2001) The adipocyte-secreted protein Acrp30 enhances hepatic insulin action. Nat Med 7:947-953

14. Yamauchi T, Kamon J, Waki H et al. (2001) The fatderived hormone adiponectin reverses insulin resistance associated with both lipoatrophy and obesity. Nat Med 7:941-946 
15. Stumvoll M, Tschritter O, Fritsche A et al. (2002) Association of the T-G polymorphism in adiponectin (exon 2) with obesity and insulin sensitivity: interaction with family history of type 2 diabetes. Diabetes 51:37-41

16. Hara K, Boutin P, Mori Y et al. (2002) Genetic variation in the gene encoding adiponectin is associated with an increased risk of type 2 diabetes in the Japanese population. Diabetes 51:536-540

17. Kondo H, Shimomura I, Matsukawa Y et al. (2002) Association of adiponectin mutation with type 2 diabetes: a candidate gene for the insulin resistance syndrome. Diabetes 51:2325-2328

18. Menzaghi C, Ercolino T, Di Paola R et al. (2002) A haplotype at the adiponectin locus is associated with obesity and other features of the insulin resistance syndrome. Diabetes 51:2306-2312

19. Vasseur F, Helbecque N, Dina C et al. (2002) Single-nucleotide polymorphism haplotypes in the both proximal promoter and exon 3 of the APM1 gene modulate adipocytesecreted adiponectin hormone levels and contribute to the genetic risk for type 2 diabetes in French Caucasians. Hum Mol Genet 11:2607-2614

20. Maeda N, Shimomura I, Kishida K et al. (2002) Dietinduced insulin resistance in mice lacking adiponectin/ ACRP30. Nat Med 8:731-737
21. Kubota N, Terauchi Y, Yamauchi T, et al. (2002) Disruption of adiponectin causes insulin resistance and neointimal formation. J Biol Chem 277:25863-25866

22. Yang WS, Jeng CY, Wu DJ et al. (2002) Synthetic peroxisome proliferator-activated receptor-agonist, rosiglitazone, increases plasma levels of adiponectin in type 2 diabetic patients. Diabetes Care 25:376-380

23. Maeda N, Takahashi M, Funahashi T et al. (2001) PPARgamma ligands increase expression and plasma concentrations of adiponectin, an adipose-derived protein. Diabetes 50:2094-2099

24. Hirose H, Kawai T, Yamamoto Y et al. (2002) Effects of pioglitazone on metabolic parameters, body fat distribution, and serum adiponectin levels in Japanese male patients with type 2 diabetes. Metabolism 51:314-317

25. Combs TP, Wagner JA, Berger J et al. (2002) Induction of adipocyte complement-related protein of 30 kilodaltons by PPARgamma agonists: a potential mechanism of insulin sensitization. Endocrinology 143:998-1007

26. Yu JG, Javorschi S, Hevener AL et al. (2002) The effect of thiazolidinediones on plasma adiponectin levels in normal, obese, and type 2 diabetic subjects. Diabetes 51:2968-2974

27. World Health Organization (1985) Diabetes mellitus: report of a WHO study group. Tech. Rep. Ser., no 727, World Health Organization, Geneva 